\title{
Multiculturalismo ou Desconstrução? Reconhecimento em Young e Fraser
}

Nathalie de Almeida Bressiani

\section{Resumo}

Partindo de uma breve exposição, focada na questão do reconhecimento dos modelos de Teoria Crítica desenvolvidos por Iris Marion Young e Nancy Fraser, esse artigo busca apresentar algumas das principais questões e dificuldades no que diz respeito à possibilidade de promover o reconhecimento das diferenças sem comprometer a igualdade e mostrar a importância da participação política e de concepções de democracia deliberativa, sem as quais parece impossível, tanto para Young quanto para Fraser, pensar adequadamente as questões de justiça nos dias de hoje.

Palavras-chave: democracia deliberativa, participação política, reconhecimento. 
No decorrer das últimas décadas, o conteúdo das demandas feitas pelos movimentos sociais vem, mundialmente, passando por profundas mudanças. Nos chamados "novos" movimentos sociais, as demandas pelo fim das desigualdades de ordem material são, cada vez mais, substituídas por demandas que visam acabar com injustiças sofridas por minorias culturais e grupos sociais classificados pela cultura dominante como inferiores ou indignos de igual respeito. $\mathrm{Na}$ medida em que cresce a relevância dada a essa nova forma de reivindicações por justiça social chamada por alguns teóricos, como Axel Honneth, Nancy Fraser e Charles Taylor, de luta por reconhecimento ou, como no caso de Iris M. Young e Willian Conolly, de política de identidade/diferença - diminui a importância atribuída às reivindicações por justiça social que têm como finalidade a obtenção de uma distribuição igualitária dos recursos e riquezas.

Tendo em vista o reconhecimento das especificidades culturais e religiosas, assim como daquelas fundamentadas em diferenças de gênero e raça, as demandas feitas pelos "novos" movimentos sociais abandonam a centralidade das categorias de trabalho e de luta de classes e se desvinculam, assim, de uma orientação voltada somente para a obtenção da igualdade econômica. Chamando atenção para essa mudança, em seu artigo "From redistribution to recognition? Dilemmas of justice in a 'postsocialist' age" , Nancy Fraser apresenta um retrato "pós-socialista" da sociedade moderna atual que, cada vez mais integrada e globalizada, teria abandonado o ideal socialista que orientava os movimentos sociais das décadas anteriores.

A condição pós-socialista diz respeito a uma alteração na gramática de reivindicações políticas. Demandas por reconhecimento das diferenças de grupos se tornaram cada vez mais salientes no período mais recente, às vezes, obscurecendo reivindicações por igualdade social. (...) A "luta por reconhecimento" está rapidamente se tornando a forma paradigmática de conflito político no final do século Xx. Demandas por "reconhecimento das diferenças" alimentam lutas de grupos mobilizados sob as bandeiras de nacionalidade, etnia, "raça", gênero e sexualidade. Nesses conflitos "pós-socialistas", identidades de grupo substituem os interesses de classe como principal termo médio de mobilização política. Dominação cultural suplanta exploração como principal injustiça e reconhecimento cultural substitui redistribuição sócio-econômica como medida contra a injustiça e objetivo das lutas políticas. ${ }^{2}$

I Nancy Fraser. "From redistribution to recognition? Dilemmas of justice in a 'postsocialist' age" In Justice Interruptus. Critical reflections on the "postsocialist" condition. New York \& London: Routledge, I997.

2 idem. ib. p. II. 
Essa mudança é claramente percebida no âmbito da tradição da Teoria Crítica, tanto no que diz respeito aos novos modelos críticos, tal como o elaborado por Honneth ${ }^{3}$, quanto nos debates que se estabeleceram entre os principais teóricos críticos. Marcado por uma pluralidade de debates e de diferentes diagnósticos do presente, assim como de modelos críticos, o cenário atual da Teoria Crítica se caracteriza pela predominância de discussões acerca das questões relacionadas ao reconhecimento. No geral, há hoje uma vasta bibliografia discutindo o multiculturalismo e o debate que se estabeleceu a respeito de como e até que ponto é possível reconhecer as diferenças e particularidades das pessoas sem que, com isso, a igualdade entre elas seja comprometida.

No interior desse debate, mostram-se de extrema importância as contribuições de algumas das principais teóricas do feminismo americano, Iris Marion Young e Nancy Fraser. Tendo passado por outras duas fases das quais a primeira foi marcada por uma disputa entre feministas pela igualdade e feministas pela diferença, e a segunda, pelo foco nas diferenças entre as mulheres, o pensamento feminista, ao se deparar com uma pluralidade de movimentos sociais, sofreu uma nova mudança e passou a se caracterizar por uma tentativa de pensar as múltiplas intersecções entre os diferentes grupos sociais ${ }^{4}$. Com vistas a essa nova fase, o pensamento feminista norte-americano se mostra indispensável para aqueles que procuram entender as demandas feitas pelos "novos" movimentos sociais e encontrar nelas o potencial crítico inscrito no presente.

Embora estejam todas voltadas para a questão do reconhecimento, cada uma das autoras, cujo pensamento será aqui desenvolvido, enfrenta a questão com um diferente enfoque e defende formas distintas de reconhecimento. Enquanto Young insiste na impossibilidade de existência de um ponto de vista neutro e, portanto, de uma teoria da justiça que tenha validade universal uma vez que todos os indivíduos são histórica e espacialmente situados; Fraser afirma que o reconhecimento deve ser entendido como uma questão de status e não de identidade e, que, em um mundo no qual a desigualdade material é exacerbada e, em muitos

3 Partindo de uma reatualização dos textos de Hegel escritos no período de Jena, e também, da utilização da psicologia social desenvolvida por George H. Mead, por meio da qual pretende dar uma inflexão empírica à filosofia idealista de Hegel, Honneth elabora seu modelo de Teoria Crítica defendendo a idéia de que os conflitos sociais devem ser compreendidos como lutas por reconhecimento. cf. Axel Honneth. Luta por reconhecimento - A gramática moral dos conflitos sociais. São Paulo: Editora 34, 2003.

4 cf. Nancy Fraser. "Multiculturalism, antiessentialism, and radical democracy: A genealogy of the current impasse in feminist theory”. In: Nancy Fraser. Justice Interruptus. ed. cit., pp.I73-I88. 
lugares, crescente, abandonar as questões de redistribuição de bens por completo ou mesmo relegá-las a um papel secundário é extremamente problemático.

Já na introdução de Justice and the politics of difference ${ }^{5}$, Young faz uma crítica ao ideal de imparcialidade que, segundo ela, é pressuposto na elaboração de todas as teorias e conceitos de justiça que se pretendem universais. Para que seja válida universalmente, uma teoria de justiça precisa ter como base fundamentos que não contenham nenhum elemento empírico, caso contrário, isto é, caso possua, por menor que seja, um fundamento que provenha da experiência, tal teoria seria historicamente situada e, portanto, parcial e não objetiva; ela não poderia ser dita válida em toda e qualquer circunstância e época, não tendo, dessa forma, validade universal. Afirmando que os atores são sempre social e historicamente situados e participam de práticas políticas e sociais concretas, Young nega a possibilidade de que eles sejam capazes de transcender suas particularidades e desenvolver teorias ou conceitos de justiça objetivos e universais. É impossível adotar um ponto de vista que abstraia toda a experiência, todas as tomadas de decisão e posição são concretamente situadas. $O$ contexto no qual cada sujeito está situado, suas experiências e perspectivas, sempre influencia as posições por ele adotadas, que não são, portanto, nunca universais.

O apelo por justiça está sempre situado em práticas sociais e políticas completas que precedem e excedem o filósofo. O esforço tradicional para transcender a finitude em direção a uma teoria universal abarca apenas construções finitas que escapam da aparência de contingência, normalmente ao tomarem o dado como necessário. (...) Particularidades de contexto e afiliação não podem nem devem ser removidas da argumentação moral. (...) O ideal da imparcialidade é uma ficção idealista. É impossível adotar um ponto de vista moral não situado e, se um ponto de vista é situado, então ele não pode ser universal, ele não tem como estar separado de e entender todos os pontos de vista. ${ }^{6}$

Partindo da impossibilidade de que um ponto de vista possa estar situado fora do mundo, Young passa a mostrar como o ideal da imparcialidade acabou resultando na universalização da perspectiva dos grupos dominantes. "[O ideal da imparcialidade] mascara as formas pelas quais as perspectivas dos grupos dominantes reivindicam universalidade e ajuda a justificar estruturas hierarquizadas de tomadas de decisão" 7 . Ao mesmo tempo em que estaria promovendo

5 Iris Young . Justice and the politics of difference, Princeton, Princeton University Press, I990.

6 idem. ib. p. 5, 97 e IO4.

7 idem. ib. p. 97. 
a universalização de uma perspectiva que é, de fato, particular, tal ideal estaria também negando e reprimindo as diferenças de três modos diversos. Primeiro: ao exigir que o sujeito abstraia suas particularidades e aja em todas as circunstâncias de acordo com as mesmas regras morais, o ideal da imparcialidade nega a ele suas especificidades. Segundo: ele procura eliminar a heterogeneidade na forma do sentimento, uma vez que, para alcançar um ponto de vista transcendente ao mundo, é preciso que o sujeito raciocinante se desvencilhe de suas inclinações e negue seus desejos e afetividades. Em terceiro lugar, como afirma Young, temos o mais importante dos modos pelos quais o ideal de imparcialidade reduz particularidades a unidade, a saber, a redução da pluralidade dos sujeitos morais a uma única subjetividade. "O juiz moral imparcial deve idealmente tratar todos da mesma forma, de acordo com os mesmos princípios aplicados imparcialmente" 8 .

Depois de rejeitar a existência de um ponto de vista transcendental, Young apresenta o que entende por Teoria Crítica, a saber, "uma reflexão normativa

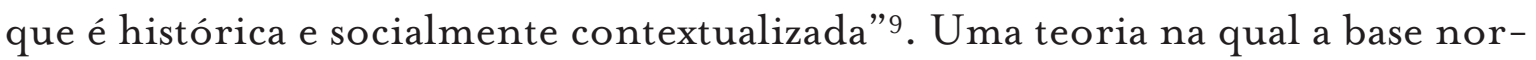
mativa da crítica deve ser encontrada nas tensões e ideais presentes na própria sociedade. Desta forma, Young pretende desenvolver uma teoria que, pautada pela experiência e pela observação das demandas feitas pelos movimentos sociais e não por fundamentações filosóficas, consiga "expressar rigorosamente e reflexivamente algumas das demandas sobre justiças e injustiças implícitas nas políticas desses movimentos e explorar seus significados e implicações"

A partir de uma análise dos movimentos sociais contemporâneos e da limitação que os paradigmas distributivos apresentam no tratamento de diversas demandas que não são redutíveis à lógica da distribuição, tal como direitos, oportunidades e auto-respeito ${ }^{\text {II }}$ Young propõe uma definição de injustiça como dominação: o constrangimento institucional à auto-determinação; e opressão:

8 Iris Young . Justice and the politics of difference, Princeton: Princeton University Press, I990, p. IOO.

9 idem. ib. p. 5 .

IO idem. ib., p.7.

II Mesmo que o paradigma distributivo tenha, na tentativa de responder às demandas dos novos movimentos sociais, ampliado o escopo da distribuição para bens não materiais, tais como oportunidades, direitos e auto-respeito, ele acaba os concebendo como coisas estáticas e não como construções intersubjetivas. "Existem, em nossa sociedade, muitas demandas por justiça e injustiça que não são primeiramente acerca de distribuição de renda, recursos ou posições. O foco na distribuição de bens e recursos restringe, inapropriadamente, o escopo da justiça porque falha em trazer estruturas sociais e contextos institucionais sob avaliação. idem. ib. p. 20. cf., idem. ib. cap. I, pp. I5-38. 
o constrangimento institucional ao auto-desenvolvimento. De acordo com essa definição que, segundo Young, recupera a maneira pela qual os novos movimentos sociais concebem a injustiça, justiça social diz respeito ao grau em que uma sociedade promove as condições necessárias para o auto-desenvolvimento, definido como desenvolvimento e exercício da capacidade dos sujeitos de expressarem suas capacidades, e à auto-determinação, entendida como participação do sujeito na determinação de suas ações e das condições destas.

Afirmando que todas as posições e pontos de vista estão concretamente situados e, portanto, não são neutros, mas sim parciais, Young defende que o ideal da imparcialidade tem, na medida em que ajuda a reproduzir e perpetuar relações de dominação e opressão, funções ideológicas. Desta forma, tendo em vista as reivindicações dos novos movimentos sociais pelo fim das relações de dominação e opressão, Young passa a defender a necessidade de que, para que uma norma seja considerada justa, é necessário que todos aqueles que são por ela afetados tenham participado igualmente de seu processo decisório e que suas perspectivas tenham sido consideradas. "Sem o ponto de vista transcendental da imparcialidade, a racionalidade das normas só pode ser fundamentada caso elas sejam entendidas como o resultado de uma discussão na qual todos os que são por elas afetados tenham sido incluídos" ${ }^{12}$.

Em Inclusion and democracy, livro no qual trata mais detidamente da questão do papel da democracia comunicativa na legitimação das normas de justiça ${ }^{13}$, Young insiste na necessidade de que todos os grupos oprimidos participem dos processos de tomada de decisão para que eles possam ser considerados justos. "Se todos aqueles que são significativamente afetados pelos problemas e suas soluções são incluídos na discussão e no processo de decisão e se eles interagem racionalmente e constituem um público no qual as pessoas são responsáveis umas pelas outras, então, é provável que os resultados da discussão sejam os mais sábios e justos” ${ }^{\text {I4 }}$. É

I2 Iris Young . Justice and the politics of difference, Princeton: Princeton University Press, I990, p. II8.

I3 Iris Young critica os modelos de democracia deliberativa que tomam a argumentação como forma privilegiada de comunicação política. Segundo ela, tais modelos estabelecem uma dicotomia entre razão e emoção que acaba desfavorecendo as mulheres, as minorias étnicas e raciais e a classe trabalhadora, cujos discursos seriam mais passionais e emocionados. Assumindo que o termo "deliberação" está carregado de conotações que privilegiariam a argumentação e o discurso não-passional nas discussões, Young prefere fazer uso do termo "democracia comunicativa" que denotaria, por sua vez, formas mais abertas de comunicação política. cf. Iris Young. Inclusion and democracy. Oxford: Oxford University Press, 2002. pp. 36-40.

I4 idem. ib. pp. 29-30. 
somente a participação igualitária de todos os grupos afetados por um problema nos processos de tomada de decisão que permite que o resultado destes não sejam, eles mesmos, expressões de relações de dominação e opressão.

Para que possamos compreender adequadamente como Young pensa a participação política, é preciso notar a importância atribuída por ela ao conceito de grupo social. Em seu primeiro livro, Justice and the politics of difference, ela chega a afirmar que os grupos sociais são anteriores aos indivíduos, uma vez que a identidade destes seria parcialmente constituída a partir de suas afinidades com diferentes grupos ${ }^{15}$. Young define opressão como um fenômeno estrutural que faz com que determinados grupos estejam, por causa de práticas sociais sistemáticas e muitas vezes inconscientes, sempre em posição de desvantagem perante os grupos dominantes. Desta forma, as relações de opressão estão sempre atreladas à noção de grupo. "Opressão faz referência a fenômenos estruturais que imobilizam ou diminuem um grupo" ${ }^{16}$. Mas, afinal, o que é um grupo? De acordo com Young um grupo social é:

uma coletividade de pessoas distinta de pelo menos um outro grupo por formas culturais, práticas ou modos de vida. Membros de um grupo têm uma afinidade específica uns com os outros em razão da similaridade de suas experiências ou modos de vidas, que os leva a se associar entre si mais do que com aqueles que não se identificam com o grupo, ou se identificam de outra maneira. ${ }^{17}$

Partindo de uma concepção forte de grupos sociais e atrelando a eles as relações de opressão, Young defende que é somente por meio da participação dos grupos oprimidos na política e nos processos de tomada de decisão que é possível fazer com que a perspectiva antes adotada como universal seja percebida como particular e o ponto de vista dos grupos oprimidos passe a influenciar as decisões. Temos, assim, que, para Young, a política não deve nem pode, para que seja justa, deixar de considerar as diferenças; pelo contrário, é somente a partir do momento em que todas as diferenças forem levadas em conta que ela poderá ser considerada legítima.

I5 "Grupos (..) constituem indivíduos. O senso de história particular a cada pessoa, assim como suas afinidades e, até mesmo, sua forma de raciocinar, valorar e expressar sentimentos são parcialmente constituídas pelas afinidades de grupo dele ou dela”. Iris Young. Justice and the politics of difference. ed. cit., p. 45 .

I6 Iris Young. Justice and the politics of difference. ed. cit., p. 42 (grifo meu).

I7 idem. ib. p. 43. 
Para que a igualdade entre os grupos seja de fato alcançada, é necessário que as especificidades de cada um deles sejam levadas em conta. Nesse sentido, Young defende a posição de centralidade que se deve dar às políticas da diferença, as quais, segundo ela, afirmam que a igualdade só pode ser realmente atingida através de um tratamento jurídico diferenciado. Leis iguais para todos, por serem insensíveis à diferença, acabam desfavorecendo alguns grupos oprimidos e, portanto, promovendo a desigualdade. "Cegueira à diferença prejudica grupos cuja experiência, cultura e capacidades sociais diferem das dos grupos privilegiados" Para garantir a igualdade entre os grupos, é preciso que suas diferenças sejam levadas em conta e que o tratamento a eles dado seja diferenciado.

Young rejeita teorias assimilacionistas, já que estas esperam que os grupos minoritários se adaptem à cultura e aos valores dos grupos dominantes, assim como aquelas que defendem que as diferenças de cultura, gênero, raça, religião e etnia não devem desempenhar nenhum papel para a sociedade e que, portanto, não devem ser consideradas na esfera política. Para ela, os grupos possuem uma identidade cultural positiva que deve ser por eles afirmada para impedir que os valores e normas de alguns grupos sejam universalizados. Medidas de caráter afirmativo são, desta maneira, vistas como uma boa estratégia para que os grupos oprimidos sejam incluídos nos processos democráticos de tomada de decisão.

Em uma luta política na qual os grupos políticos insistem no valor positivo de suas culturas e experiências específicas, torna-se cada vez mais difícil para os grupos dominantes estabelecerem suas normas como neutras e universais e construir os valores e comportamentos dos oprimidos como desviante, pervertidos ou inferiores. (...) Ao atribuir um sentido positivo para suas próprias identidades, grupos oprimidos buscam conquistar o poder de nomear a própria diferença e explodir as definições implícitas de diferença como desvios em relação a norma, que cristaliza alguns grupos em uma natureza auto-limitada. ${ }^{19}$

Ao defenderem a necessidade e importância de ações políticas por meio das quais os grupos possam afirmar positivamente suas identidades, as políticas da diferença defendidas por Young correm o risco de congelar identidades que estão em constante mudança e que não podem, portanto, ser entendidas como fixas. Consciente dessa possível conseqüência, Young insiste que

I8 Iris Young . Justice and the politics of difference, Princeton: Princeton University Press, I990, p.I64. I9 idem. ib. pp. I66 e I7I. 
os grupos devem construir suas identidades de maneira reflexiva e que estas sejam sempre entendidas como fluidas, caso contrário, as políticas da diferença podem resultar na reificação das identidades. Outro problema, também reconhecido por Young, é a possibilidade de que, ao afirmarem suas identidades, os grupos estejam afirmando diferenças que tenham como causa a própria opressão. Desta forma, eles acabariam afirmando diferenças que não deveriam existir. A este problema Young responde defendendo que, mesmo que talvez tais diferenças ${ }^{20}$ não devessem existir, elas existem, e que ignorálas resultaria em uma situação desvantajosa para alguns grupos. Ignorar as diferenças existentes hoje entre homens e mulheres, afirma Young, "às vezes prejudica as mulheres em locais públicos, onde normas e estilos masculinos predominam”2I.

A forte defesa do multiculturalismo e de políticas de diferença, presentes na teoria apresentada por Young, são alvos de críticas de diversas outras feministas, como Fraser. Além de acusar a teoria de Young de não conseguir abarcar adequadamente os problemas de desigualdade social, Fraser aponta alguns problemas na adoção de uma estratégia multiculturalista. Segundo ela, políticas de afirmação da diferença tendem a intensificá-las, assim como promover simplificações de identidades e comunistarismo repressivo.

Em "Culture, political economy, and difference" ${ }^{22}$, Fraser reconhece o caráter inovador do trabalho de Young, que procura abarcar tanto questões de reconhecimento quanto de redistribuição. Para Fraser, no entanto, mesmo tentando dar conta de ambas as questões por meio de uma teoria monística que entende todas as injustiças como formas de opressão, Young não teria conseguido escapar de uma concepção dual de injustiça que diferencia as injustiças de caráter político econômico de outras que possuem caráter cultural. A classificação apresentada por Young de cinco tipos diferentes de opressão que, em conjunto, dariam conta da totalidade das injustiças presentes na sociedade, isto é, exploração, marginalização, falta de poder, imperialismo cultural e violência ${ }^{23}$, estaria, para Fraser, estruturada a partir de uma distinção entre injustiças arrai-

20 Young tem em mente as supostas diferenças entre homens e mulheres. $c f$. Iris Young. Justice and the politics of difference, Princeton: Princeton University Press, I990, pp. I75 e ss.

2I idem. ib. p. I76.

22 Nancy Fraser. "Culture, political economy, and difference - On Iris Young's justice and the politics of difference". In: Justice Interruptus. ed. cit., pp.I89-205.

23 Para uma conceitualização detalhada das diferentes faces de opressão apresentadas por Young ver: Iris Young. Justice and the politics of difference. ed. cit., pp. 39-65. 
gadas na estrutura político econômica da sociedade, às quais corresponderiam opressões na forma de exploração, marginalização e falta de poder, e injustiças culturais, às quais corresponderiam imperialismo cultural e violência.

O que ocorre, entretanto, é que, mesmo presentes, as questões de redistribuição levantadas por Young permanecem, em sua teoria, ocupando uma posição secundária. $O$ centro gravitacional de Justice and the politics of difference, como afirma Fraser, é a questão do reconhecimento. O objetivo de Young é elaborar uma teoria que esteja implícita nas reivindicações dos novos movimentos sociais. Dessa forma, é na teorização do reconhecimento que Young encontra a realização de seu projeto central. As políticas de identidade, cuja necessidade é defendida por Young no decorrer do livro, não dão conta, de acordo com Fraser, de injustiças que tenham sido geradas a partir da economia política.

A proposta defendida por Young estabelece a necessidade de que opressões culturalmente enraizadas sejam combatidas por meio de uma revolução cultural que faria, por meio de políticas de afirmação das diferenças, com que as variações culturais deixassem de ser vistas como desvios em relação ao conjunto de normas dominantes. "Isso significa acabar com a idéia de um conjunto único e universal de normas culturais e afirmar pluralismo cultural e diferenças" ${ }^{24}$. Injustiças de caráter econômico, no entanto, para serem combatidas exigem uma reestruturação da divisão do trabalho. "O que inclui, por exemplo, a eliminação da divisão entre aqueles que definem e aqueles que executam o trabalho e provisão de atividades socialmente valorizadas para todos" ${ }^{25}$.

Tendo isso em vista, Fraser aponta uma possível contradição na qual desembocaria a teoria desenvolvida por Young. Enquanto injustiças arraigadas nos padrões culturais institucionalizados da sociedade exigiriam, para serem sanadas, a afirmação das diferenças as quais promoveriam uma diferenciação entre os grupos, as medidas exigidas para que se acabe com injustiças de caráter econômico tenderiam a diminuí-la. Desta forma, "em alguns casos, os efeitos das duas medidas serão contraditórios" ${ }^{26}$.

Temos, assim, que, para Fraser, as políticas da diferença defendidas por Young, na medida em que promovem a afirmação das diferentes identidades, produzem efeitos negativos àqueles desejados pelas medidas que visam acabar com desigualdades materiais. Fica, então, clara a incompatibilidade entre políticas de diferença e medidas que buscam igualdade material. Como conseqüência, temos

24 Nancy Fraser. "Culture, political economy, and difference". op. cit., p.I99.

25 idem. ib.

26 idem. ib. 
que mesmo que a teoria desenvolvida por Young tenha tentado dar conta de questões de redistribuição, ela não conseguiu fazê-lo de forma adequada. A partir de uma definição que não diferencia os grupos sociais, isto é, a partir de um conceito de grupo social que engloba tanto grupos culturais quanto grupos baseados na economia política e de uma teoria que propõe para todos os grupos políticas de diferença como meios para se acabar com a opressão, Young não conseguiu abarcar de maneira satisfatória as questões de redistribuição. Ao elaborar o conceito de grupo social ou ao defender a necessidade de políticas de diferença, Young parece ter em mente somente os problemas de reconhecimento; a reestruturação da divisão do trabalho necessária para que se atinja o fim das desigualdades materiais não tem como ser alcançado por meio de políticas de diferença.

O modelo de Teoria Crítica apresentado por Fraser tenta dar conta da aparente contradição que se estabelece entre políticas de redistribuição e políticas de reconhecimento, quando as segundas são entendidas em termos da afirmação de identidades, e conceitualizar, de maneira adequada, questões de reconhecimento e de redistribuição.

Em uma recente reformulação de sua teoria, Fraser passa a adotar como base um princípio universal que possibilite a avaliação das reivindicações dos diferentes movimentos sociais e o estabelecimento de, dentre elas, quais são legítimas. Retomando os princípios da Moralität kantiana ${ }^{27}$, no que se refere a sua obrigatoriedade, o modelo de Teoria Crítica desenvolvido por Fraser parte de uma teoria da justiça que tem como base o princípio de paridade de participação. Princípio este que, como afirma a autora, é universalmente obrigatório e, portanto, mantém, independentemente dos atores, um comprometimento com valores específicos, os quais afirmam que uma sociedade, para que seja justa, precisa dar condições para que todas as pessoas que nela vivem participem como pares na vida social.

As injustiças são, desta forma, vistas como resultado do status quo de uma sociedade. São elas que impedem que todos os sujeitos possam participar da vida social como iguais. Fraser concebe sua teoria a partir da participação igualitária de todos os indivíduos não só nas deliberações democráticas, mas também

27 "No campo da filosofia moral, questões de justiça são normalmente entendidas como assuntos concernentes ao 'justo', que pertence ao terreno da 'moralidade'. (...) Normas de justiça são universalmente obrigatórias; como os princípios da Moralität kantiana, eles mantêm, independentemente dos atores, um comprometimento com valores específicos". Nancy Fraser. "Social justice in the age of identity politics: redistribution, recognition, and participation”. In: Redistribution or Recognition? A PoliticalPhilosophical Exchange. New York \& London: Verso. 2003, p. 28. 
na vida e na realidade social como um todo. É, então, partindo de uma teoria da justiça que ela identifica duas formas distintas de injustiça, uma delas relacionada à redistribuição e a outra, ao reconhecimento, já que, para que uma sociedade seja justa, isto é, para que satisfaça o princípio de paridade de participação, é necessário que essas duas condições sejam satisfeitas. É preciso que haja igualdade material de modo a garantir aos participantes independência e voz, assim como padrões institucionalizados de valor cultural que expressem respeito igual a todos os participantes. Portanto, afirma Fraser, tanto redistribuição quanto reconhecimento se colocam como necessários para que se obtenha uma sociedade justa, de maneira que o importante agora seria analisar como se relacionam, na prática, redistribuição e reconhecimento.

No que diz respeito a isso, Fraser se opõe aos economicistas ao defender que não é possível explicar satisfatoriamente questões de não-reconhecimento reduzindo-as a um reflexo da desigualdade material e nega também a visão dos culturalistas, dentre os quais inclui Honneth, que acredita ser possível explicar os problemas de redistribuição material recorrendo à valoração cultural corrente em cada sociedade. Fraser defende que tanto políticas de redistribuição de bens materiais quanto de reconhecimento se colocam como necessárias à realização de uma sociedade justa. Isso porque, embora injustiças econômicas e culturais estejam interligadas na prática, as primeiras têm suas raízes na estrutura político-econômica da sociedade, enquanto as últimas estão arraigadas em padrões sociais de representação. Injustiças culturais e econômicas têm origens distintas e, mesmo que na prática sejam indissociáveis e relacionadas de tal modo que se reforcem mutuamente, elas não podem ser reduzidas umas às outras. Desta maneira, cada uma das duas formas de injustiça precisa de recursos distintos para ser combatida; tanto políticas de redistribuição quanto de reconhecimento se colocam como necessárias.

A diferenciação entre essas duas formas distintas de injustiça é, no entanto, apenas analítica. Como afirma a própria autora em diversos artigos, na sociedade, desigualdade material e falta de reconhecimento aparecem sempre juntas mesmo que em diferentes proporções. As injustiças sofridas pela classe trabalhadora seriam, assim, as que mais perto chegariam de injustiças derivadas puramente da estrutura-político econômica da sociedade, enquanto aquelas sofridas por homossexuais, as que chegariam mais próximo de injustiças derivadas dos padrões institucionalizados de valores culturais. Questões de gênero, assim como questões raciais, já estariam, de acordo com a autora, mais afastadas dos dois extremos e fariam parte do que ela chama de injustiças bidimensionais, a saber, injustiças que derivam diretamente da estrutura político-econômica assim como de padrões de valores culturais de uma sociedade. 
Desta forma, enquanto as injustiças sofridas pela classe trabalhadora precisariam, para serem combatidas, de políticas de redistribuição material e aquelas sofridas por sexualidades menosprezadas de políticas, de reconhecimento, as injustiças sofridas, por exemplo, por negros e mulheres, precisariam de ambas, isto é, políticas de redistribuição assim como de reconhecimento.

O que ocorre, entretanto, é que estas duas formas distintas, analiticamente, de injustiças são muitas vezes vistas como excludentes. Isto porque se vê como finalidade das reivindicações por justiça redistributiva a abolição das diferenças e não o seu reconhecimento, ao mesmo tempo que se atribui como fim das políticas de reconhecimento o reconhecimento das especificidades e, portanto, das diferenças de determinados grupos. Segundo Fraser, no entanto, esta contradição é resultado da associação de políticas de reconhecimento com políticas de identidade ou políticas de diferença, tais como as defendidas por Young, o que, por sua vez, faria com que as políticas de reconhecimento fossem reduzidas a reivindicações pela afirmação das especificidades de parcelas menosprezadas da população.

Negando esta aparente contradição, o modelo de Teoria Crítica apresentado por Fraser diferencia dois caminhos que podem ser percorridos no intuito de acabar com as duas formas de injustiça. O primeiro é o recurso afirmativo: nele estão contidas medidas que, ao lidar com as conseqüências de um sistema que gera desigualdades sem alterá-lo, não chegam a tratar das causas do problema. No contexto da redistribuição, medidas de caráter afirmativo consistem na distribuição de impostos na forma de saúde, transporte e educação para a população mais pobre. Este tipo de medida poderia ocasionar efeitos inversos aos desejados, causando problemas de reconhecimento, visto que possibilita uma visão dos pobres como uma classe parasitária. Efeitos de caráter negativo podem resultar também da utilização de medidas afirmativas que tentem solucionar injustiças de reconhecimento, isto porque, no contexto do reconhecimento, tais medidas incentivam o reconhecimento das diferenças e, conseqüentemente, as intensificam.

Relacionando medidas afirmativas de reconhecimento com o multiculturalismo, estratégia presente em teorias como a de Young, Fraser tenta mostrar que essas medidas acabam por intensificar as diferenças. Em seu artigo "Rethinking recognition”, Fraser critica a posição adotada pelos multiculturalistas, assim como aquela defendida por aqueles que vêem o reconhecimento como uma questão de identidade, e levanta contra eles dois problemas. O primeiro deles, intitulado pela autora de "problema de deslocamento" ou de "substituição", tenta mostrar como as teorias do reconhecimento, ao invés de enriquecer e complementar as lutas por redistribuição material, acabam por marginalizá-las, relegando-as a um 
plano secundário ou mesmo substituindo-as por completo. Dentre as teorias que cairiam nesse problema, Fraser identifica duas categorias diferentes. De um lado estão aquelas que negligenciariam como um todo as questões relacionadas a desigualdade material e, de outro, aquelas que, como a de Honneth, tentam explicar a desigualdade material através da valoração cultural corrente na sociedade. O segundo problema levantado por Fraser é o que ela chama de "reificação", o reconhecimento visto sob as lentes de um modelo de políticas de identidade tende a cristalizar a identidade de grupos. Isto porque, ressaltando a necessidade de elaboração e exibição de uma identidade coletiva autêntica, auto-afirmada e auto-gerada, o modelo de políticas de identidade pressiona os indivíduos a se conformarem com a cultura de um grupo já existente. Como efeito, temos a imposição de uma identidade de grupo única e drasticamente simplificada, que nega aos indivíduos a complexidade e multiplicidade de suas identificações. O multiculturalismo tenderia, portanto, a reforçar uma dominação dentro dos próprios grupos, levando a formas repressivas de comunistarismo e promovendo conformismo e intolerância ${ }^{28}$.

Como alternativa ao modelo de políticas de identidade, isto é, ao multiculturalismo, Fraser propõe uma forma diferente de ver o reconhecimento. Ao invés de tomá-lo como designação de uma relação recíproca ideal entre sujeitos na qual cada um vê o outro como igual ao mesmo tempo em que se percebe como separado dele, Fraser o entende como uma questão de status de subordinação. A falta de reconhecimento não deve ser entendida como um impedimento à formação da identidade, isto é, como uma questão de autorealização; o reconhecimento de um indivíduo, ou de um grupo, por outros indivíduos não deve ser visto como condição necessária para a constituição de uma subjetividade sem distorções. Isto porque, de acordo com ela, a injustiça é resultado do status quo de uma sociedade e diz respeito ao impedimento do sujeito de participar da vida social como igual. Sob essa perspectiva, aquele que sofre de falta de reconhecimento é o sujeito ao qual o status de parceiro paritário nas interações sociais é negado. Partindo dessa compreensão do que seria a falta de reconhecimento, Fraser defende que, para combatê-la, é necessário que as relações de subordinação sejam abolidas e não que as identidades de grupo sejam valorizadas.

É preciso desinstitucionalizar padrões de valores culturais que impedem a participação igualitária de todos os indivíduos na vida social. Para tanto, ela elabora, a partir de Derrida, um conceito de desconstrução que a permite de-

28 cf. Nancy Fraser. "Rethinking Recognition”. In: New Left Review, n. 3, 2000, p. IO7-I20. 
fender que, ao invés de incentivar o reconhecimento das diferenças, deve-se desconstruir as dicotomias presentes na sociedade, tais como as entre branco e negro, homossexual e heterossexual, homem e mulher.

Esta Segunda abordagem corrige as subordinações de status desconstruindo as oposições simbólicas que subjazem aos padrões de valores culturais correntemente institucionalizados. Longe de simplesmente aumentar a auto-estima dos que não são reconhecidos, ela desestabilizaria diferenciações de status existentes e mudaria a auto-identidade de todos. ${ }^{29}$

As medidas transformativas, tais como a desconstrução, em contraposição às afirmativas, têm como objetivo a alteração do sistema que gera as desigualdades: são medidas orientadas "para a correção de resultados indesejáveis precisamente pela reestruturação do arcabouço genérico que os produz" ${ }^{\circ}$. Estratégias transformativas são, portanto, preferíveis às afirmativas, embora não estejam elas mesmas isentas de dificuldades. O que ocorre, no entanto, é que demandas por medidas transformativas estão descoladas dos interesses imediatos de grande parte das lutas sociais.

Em alguns casos, como ressalta a autora em seu artigo "Institucionalizing democratic justice", medidas que, em um primeiro momento, parecem afirmativas podem, em determinados contextos, ter efeitos transformativos e criar um terreno mais favorável a outras mudanças. Em Redistribuition or recognition?, Fraser tenta escapar deste problema propondo uma terceira via que combina o melhor das medidas afirmativas com o melhor das transformativas. Esta via média seria necessária porque as estratégias transformadoras se mostram, no momento, politicamente impraticáveis, e as afirmativas, apesar de viáveis, contêm falhas e efeitos negativos. A finalidade desta via seria possibilitar, através da utilização das estratégias afirmativas, mudanças na realidade social que viabilizassem a prática de estratégias transformativas. A longo prazo, a combinação destas medidas ocasionaria mudanças na estrutura da realidade tal como ela se apresenta hoje.

É, no entanto, necessário ressaltar que a proposta defendida por Fraser acerca da adoção de medidas de caráter transformativo que, no caso do reconhecimento, consistiriam na desinstitucionalização de padrões de valores cul-

29 Nancy Fraser. "Social Justice in the age of identity politics redistribution, recognition, and participation”. ed. cit., p.75.

30 Nancy Fraser. "Da redistribuição ao reconhecimento? Dilemas da justiça da era pós-socialista”, ed. cit., p. 266. 
turais que impedem a participação igualitária, ou da adoção de vias médias que combinassem medidas afirmativas e transformativas, não pode ser entendida de forma prescritiva. Na reformulação de sua teoria, Fraser muda o tom por meio do qual faz referência à distinção entre medidas transformativas e afirmativas. Embora permaneça defendendo que as primeiras são mais adequadas, Fraser reconhece que o conteúdo da justiça social só deve ser determinado através de deliberações públicas e que, portanto, são os próprios concernidos que devem decidir a quais políticas querem lançar mão. Ela não pode determinar antecipadamente aquilo que, como ela mesma defende, só pode ser decidido por meio de deliberações em que todos possam participar igualmente. Desta forma, ao mostrar-se favorável às medidas transformativas, Fraser pretende apenas desempenhar o papel de teórica, isto é, trazer à luz algumas das conseqüências que ela acredita resultarem da adoção de medidas afirmativas, assim como as que se seguiriam da adoção de medidas transformativas. No entanto, não cabe a ela decidir dentre elas quais são mais adequadas; isto só pode ser decidido por meio de deliberações públicas ${ }^{3 \mathrm{I}}$.

A partir de uma breve contraposição, focada na questão do reconhecimento, entre os modelos de Teoria Crítica elaborados por Iris Young e por Nancy Fraser, é possível notar algumas das principais dificuldades envolvidas na tentativa de teorizar questões de reconhecimento, isto é, de elaborar uma teoria que possibilite o reconhecimento das diferenças sem comprometer a igualdade entre os sujeitos. Fica, no entanto, clara a importância da participação política e de concepções de democracia deliberativa, sem as quais parece impossível, tanto para Young quanto para Fraser, pensar adequadamente as questões de justiça nos dias de hoje. Mesmo

3I Em seu artigo "The point of recognition", o último do livro no qual estabelece um diálogo com Fraser, Honneth sustenta uma crítica que, no mesmo sentido da que foi nesse parágrafo apresentado, acusa Fraser de cair em contradição e antecipar aquilo que, como ela mesma sustenta, só pode ser resultado da deliberação. A crítica apresentada por Honneth, no entanto, diz respeito ao próprio estabelecimento do principio de paridade de participação como fundamento deontológico da teoria da justiça elaborada por Fraser. Em sua tentativa de fundamentar deontológicamente o principio de paridade de participação, Fraser se depara com inúmeras dificuldades. "Fraser quer entender sua abordagem em consonância com o modelo deontológico procedimental, no qual os deveres da justiça social devem derivar dos resultados da deliberação pública, na qual todos os membros da sociedade, em razão de sua igual autonomia, estão aptos a participar. (...) O verdadeiro problema nessa concepção do procedimento por ela defendido, no entanto, é que Fraser parece antecipar repetidamente os resultados desses debates entendidos como procedimento, explicando, ela mesma, o conteúdo material da justiça social". cf. Axel Honneth. "The point of recognition: a rejoinder to the rejoinder". In: Redistribution or Recognition?. ed. cit., p. 26I. 
defendendo o uso de estratégias distintas à promoção do reconhecimento, ambas desenvolvem seus modelos de Teoria Crítica partindo de uma teoria democrática na qual a participação política desempenha um papel fundamental.

\section{Referências Bibliográficas}

Benhabib, Seyla. The claims of culture. Equality and diversity in the global era. Princeton: Princeton University Press, 2002a.

Benhabib, Seyla. "On culture, public reason, and deliberation: Response to Pensky and Peritz". In: Constellations. v. II, n. 2, 2004, p. 29I-299.

FraSer, Nancy. Justice interruptus. Critical Reflections on the "postsocialist" condition. New York \& London: Routledge, I997.

FraSer, Nancy. "Rethinking recognition". In: New Left Review. n. 3, 2000, p. IO7-I2O.

FraSER, Nancy. "Social justice in the age of identity politics: redistribution, recognition, and participation". In: Redistribution or recognition? A political-philosophical exchange. New York \& London: Verso. 2003.

FrASER, Nancy. "Distorted beyond all recognition: a rejoinder to axel honneth". In: Redistribution or recognition? A political-philosophical exchange. New York \& London: Verso. 2003.

FRASER, Nancy. "Institutionalizing democratic justice: redistribution, recognition, and rarticipation”. In: Pragmatism, critique and judgment. Mit Press, 2004.

Honneth, Axel. "The point of recognition: a rejoinder to the rejoinder". In: Redistribution or recognition? A political-philosophical exchange. New York \& London: Verso, 2003.

Neves, Raphael G. S. Reconhecimento, multiculturalismo e direitos. Contribuições do debate feminista a uma Teoria Crítica da sociedade. Dissertação de mestrado. São Paulo: Dep. de Giência Política, Fflah - USP, 2005. 
Young, Iris M. Justice and the politics of difference. Princeton: Princeton University Press, I990.

Young, Iris M. "Comments on Seyla Benhabib, situating the self". In: New German Critique. n. 62. I994, p. I65-I72.

YounG, Iris M. "Unruly categories: A critique of Nancy Fraser's dual system theory". In: New Left Review. n. 222. 1997, p. I47-I60.

Young, Iris M. Inclusion and democracy. Oxford: Oxford University Press, 2002.

ZuRn, Christopher. "Identity or status? Struggles over "recognition" in Fraser, Honneth, and Taylor". In: Constellations. v. IO. n. 4. 2003, p. 519-537.

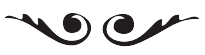

Nathalie de Almeida Bressiani é graduanda em filosofia pela USP e bolsista pela FAPESP.

E-mail: nathbressiani@gmail.com. 